\title{
Posterior Cingulate Cortical Response to Active Avoidance Mediates the Relationship between Punishment Sensitivity and Problem Drinking
}

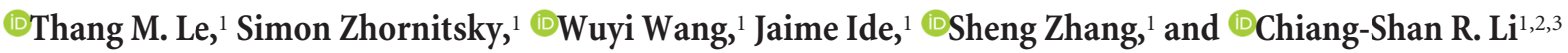 \\ ${ }^{1}$ Department of Psychiatry, and ${ }^{2}$ Department of Neuroscience, and ${ }^{3}$ Interdepartmental Neuroscience Program, Yale University School of Medicine, New \\ Haven, Connecticut 06520
}

\begin{abstract}
Many people drink to alleviate negative affect, reflecting an avoidance strategy which can lead to alcohol misuse. Individuals with heightened sensitivity to punishment (SP) are especially susceptible to problem drinking via this maladaptive coping mechanism. As imaging studies have largely focused on sensation-seeking traits and approach behavior, the neural substrates underlying behavioral avoidance as well as their relationship with punishment sensitivity and alcohol use remain unclear. Here, we examined in humans the cerebral correlates of response inhibition to avoid a penalty in relation to both problem drinking and SP, as evaluated by the Alcohol Use Disorders Identification Test and the Sensitivity to Punishment and Sensitivity to Reward Questionnaire, respectively. Seventy nondependent female and male drinkers performed a reward go/no-go task with approximately two-thirds go and one-third no-go trials. Correct go and no-go responses were rewarded, and incorrect responses were punished. The results showed that SP and Alcohol Use Disorders Identification Test scores were both positively correlated with brain activations during response inhibition, and these activations overlapped in the posterior cingulate cortex (PCC). Thus, the PCC may represent a shared neural substrate for avoidance, punishment sensitivity, and problem drinking. Mediation analyses further suggested that PCC response to avoidance completely and bidirectionally mediated the relationship between SP and hazardous alcohol use. These findings substantiated the role of the PCC in behavioral avoidance and its link to problem drinking in punishment-sensitive nondependent drinkers.
\end{abstract}

Key words: alcohol; avoidance; go/no-go; posterior cingulate cortex; problem drinking; punishment sensitivity

Significance statement

Many people drink to alleviate negative affect, reflecting an avoidance strategy that can lead to alcohol misuse. Individuals with heightened punishment sensitivity (SP) trait are particularly vulnerable to this maladaptive coping mechanism. The current study examined the neural substrates underlying behavioral avoidance and their relationship with SP and problem drinking. Using a reward go/no-go task, we showed both SP and drinking severity were positively correlated with the posterior cingulate cortex (PCC) activation during action inhibition. Thus, the PCC may represent a shared neural substrate for avoidance behavior, punishment sensitivity, and problem drinking. Further, PCC response to avoidance mediated the relationship between SP and alcohol use. These findings substantiated the neural processes linking avoidance tendency to alcohol misuse in punishment-sensitive drinkers.

\section{Introduction}

In the Motivational Model of Alcohol Use (Cox and Klinger, 1988; Cooper et al., 1995), drinking motives (i.e., reasons to

\footnotetext{
Received March 5, 2019; revised June 4, 2019; accepted June 6, 2019.

Author contributions: T.M.L. and S. Zhang analyzed data; T.M.L., S. Zhornitsky, W.W., J.I, S. Zhang, and C.-S.R.L. wrote the first draft of the paper; T.M.L., S. Zhornitsky, W.W., J.I., S. Zhang, and C.-S.R.L. edited the paper; T.M.L., S. Zhornitsky, W.W., J.I., S. Zhang, and C.-S.R.L. wrote the paper; S. Zhornitsky and W.W. performed research; C.-S.R.L. designed research.

This work was supported by National Institutes of Health Grants AA021449, DA023248, DA044749, EB022911, and MH113134. The National Institutes of Health otherwise had no roles in the conceptualization of the study, execution of the experiments, data analysis, or in the decision to publish the results.
}

drink) play a critical role in alcohol misuse. Underlying these motives are individual differences in trait sensitivity (e.g., sensitivity to reward [SR] vs punishment) and behavioral tendency (e.g., approach vs avoidance), which are known to influence drinking behavior (Loxton and Dawe, 2001; Wiers et al., 2011; Adams et al., 2012). Specifically, individuals with heightened SR

\footnotetext{
The authors declare no competing financial interests. Correspondence should be addressed to Thang M. Le at thang.le@yale.edu. https://doi.org/10.1523/JNEUROSCI.0508-19.2019 Copyright $\odot 2019$ the authors
} 
drink to enhance mood (Cooper, 1994; Hittner and Swickert, 2006), whereas those with heightened sensitivity to punishment (SP) drink to avoid or escape from negative emotions (Cooper, 1994; Stewart and Devine, 2000; Merrill and Read, 2010). Drinking as an avoidance strategy, in particular, has been associated with excessive alcohol consumption (Holahan et al., 2001), alcohol dependency (Cooper et al., 1995), and relapse among recovering alcoholics (Marlatt and Gordon, 1980; Wunschel et al., 1993). Understanding the motivational processes and the underlying neural bases of behavioral avoidance in drinkers, therefore, can help formulate appropriate interventions.

Despite the link between avoidance coping and alcohol use, previous studies have largely focused on how personality traits associated with approach tendency dispose individuals to problem drinking (Franken, 2002; Knyazev et al., 2002; Pardo et al., 2007; Tapper et al., 2015), including sensation-seeking (Hittner and Swickert, 2006) and impulsivity (Grau and Ortet, 1999; King et al., 2014). With brain imaging, investigators have characterized the neural correlates of these personality traits in alcohol dependence (Koob et al., 1994; Addolorato et al., 2005; Olbrich et al., 2006; Bobova et al., 2009; Weiland et al., 2013; Heinrich et al., 2016; Galandra et al., 2018). In contrast, while several studies have related measures of avoidance traits, such as neuroticism (Stewart and Devine, 2000; Kuntsche et al., 2008) and behavioral inhibition (Hasking, 2006) to alcohol misuse, no work to our knowledge has examined the neural substrates linking behavioral avoidance to problem drinking.

The go/no-go (GNG) task featuring both reward and punishment contingencies has been used to assess avoidance coping and cognitive processing of aversive feedback in anxious individuals (Shane and Peterson, 2004) as well as impairment in passive avoidance in relation to psychopathic traits (Newman and Schmitt, 1998). Other studies used response time (RT) and error rates in the GNG task to quantify approach and avoidance tendencies to alcohol cues in dependent and nondependent drinkers (Houben et al., 2012; Kreusch et al., 2014). However, no investigations have examined the neural processes of behavioral avoidance with the GNG task and how these neural processes may be recruited in relation to personality traits or to alcohol misuse. An important consideration is that drinkers may drink both to avoid negative affect and to experience the rewarding effects of alcohol (Cooper, 1994). Thus, it is critical to incentivize both go and no-go responses to examine the influence of trait sensitivity on the neural processes underlying problem drinking.

Here, we characterized the brain substrates underpinning the motivation of alcohol use by investigating how drinking may be related to the neural processes supporting approach and avoidance behaviors and how this relationship is influenced by punishment sensitivity. We used a GNG task, which rewarded correct and penalized incorrect responses in both go $(\sim 67 \%)$ and no-go $(\sim 33 \%)$ trials. The no-go responses required inhibition of action to avoid monetary loss, thus reflecting goal-directed behavioral avoidance. The Sensitivity to Punishment and Sensitivity to Reward Questionnaire (Torrubia et al., 2001) and Alcohol Use Disorders Identification Test (AUDIT) (Saunders et al., 1993; Babor et al., 2001) were used to evaluate trait sensitivity and drinking behavior, respectively. We tested the hypothesis that heightened SP and AUDIT scores would both be associated with increases in brain activation to no-go versus go responses, reflecting the potentially convergent neural processes of trait sensitivity, behavioral avoidance, and alcohol misuse. Finally, we conducted a mediation analysis involving SP score, AUDIT score, and brain activity to delineate their interdependent relationships.

\section{Materials and Methods}

\section{Experimental design and statistical analysis}

Participants. Seventy healthy adults ( 36 women; age $=35.9 \pm 13.8$ years, mean \pm SD) participated in the study. All subjects were screened to be free from major medical, including neurological illness and Axis I psychiatric disorders. No participants were currently on psychotropic medications, and all tested negative for illicit substances on the study day. Subjects provided written informed consent after details of the study were explained, in accordance to institute guidelines and procedures approved by the Yale Human Investigation Committee.

Assessment and behavioral task. Participants completed the Sensitivity to Punishment and Sensitivity to Reward Questionnaire (Torrubia et al., 2001), which contains 48 yes-no items, with 24 items measuring behavioral impulsivity/responsiveness to reward and the other 24 measuring behavioral avoidance in response to potentially adverse consequences. Scores were obtained by totaling the number of yes answers in each scale, with higher subscores indicating greater SR and SP, respectively. Participants reported an average SR score of $9.86 \pm 4.78( \pm$ SD) and SP score of $8.74 \pm 5.32$. Across participants SR and SP scores were not significantly correlated $(r=0.21, p=0.08)$. Participants also completed the AUDIT (Saunders et al., 1993; Babor et al., 2001). AUDIT scores are calculated from the sum of 10 self-report questions: with 3 questions on quantity of alcohol use, 4 on alcohol-related problems and adverse reactions, and 3 on drinking behavior. Each question receives a score ranging from 0 to 4 . A higher score indicates a greater risk for having or developing an alcohol use disorder. Participants reported an average AUDIT score of $10.3 \pm 10.4( \pm \mathrm{SD})$, suggesting moderate severity and significant intersubject variation in the degree of problem drinking.

Each participant completed four sessions of the GNG task (see Fig. 1). The dollar/nickel rewards were shown to the left/right of the fixation in two sessions and were reversed in location for the other two sessions, with the order counterbalanced across subjects. In each session, go (green square, $\sim 66.6 \%$ ) and no-go (red square, $\sim 33.3 \%$ ) trials were randomly intermixed in presentation, with an intertrial interval of $3 \mathrm{~s}$.

At the beginning of each trial, two squares outlined in white and overlaid on a dollar/nickel image appeared each to the left and right of fixation. After a randomized interval (fore-period) between 1 and $5 \mathrm{~s}$, one of the squares turned green/red, instructing a GNG response. Subjects were instructed to press the spatially corresponding left/right button as quickly as possible in response to the go signal, and to withhold the button press to the no-go signal to receive the reward. Feedback was provided at button press or after the response window had elapsed with an image of a dollar or nickel shown to indicate the money won, and an " $\mathrm{X}$ " on the dollar or nickel image to indicate the money lost due to incorrect responses. A premature button press before the color change would result in an error with the dollar or nickel image overlaid with an $\mathrm{X}$. Across the 4 runs, participants completed $\sim 100$ go dollar trials, 100 go nickel trials, 50 no-go dollar trials, and 50 no-go nickel trials.

Before imaging, each subject completed a control session outside the scanner. The control GNG task was identical to the experimental task but contained no reward stimuli and resulted in no reward. A normal distribution function was fitted on the RT, and $10^{7}$ data points were generated based on the fitted function. The response window for go success was set as the closest integer $>85 \%$ of the generated data points for the fMRI experiment. Participants received actual winnings from the task with an average payment of $\$ 107.4$ ( $\pm \$ 31.1 \mathrm{SD})$.

Imaging protocol and data preprocessing. Conventional T1-weighted spin echo sagittal anatomical images were acquired for slice localization using a 3T scanner (Siemens Trio). Anatomical 3D MPRAGE images were obtained with spin echo imaging in the axial plane parallel to the anterior commissure-posterior commissure line with $\mathrm{TR}=1900 \mathrm{~ms}$, $\mathrm{TE}=2.52 \mathrm{~ms}$, bandwidth $=170 \mathrm{~Hz} /$ pixel, $\mathrm{FOV}=250 \times 250 \mathrm{~mm}$, matrix $=256 \times 256,176$ slices with slice thickness $=1 \mathrm{~mm}$ and no gap. Functional BOLD signals were acquired using multiband imaging (multiband acceleration factor $=3$ ) with a single-shot gradient EPI sequence. Fifty-one axial slices parallel to the anterior commissure-posterior commissure line covering the whole brain were acquired with TR $=1000 \mathrm{~ms}$, 
$\mathrm{TE}=30 \mathrm{~ms}$, bandwidth $=2290 \mathrm{~Hz} /$ pixel, flip angle $=62^{\circ}, \mathrm{FOV}=210 \times$ $210 \mathrm{~mm}$, matrix $=84 \times 84$, slice thickness $=2.5 \mathrm{~mm}$ and no gap.

Imaging data were preprocessed using SPM8 (Wellcome Trust Centre for Neuroimaging). Images from the first five TRs at the beginning of each run were discarded to ensure only BOLD signals at steady-state equilibrium between RF pulsing and relaxation were included in analyses. Images of each individual subject were first realigned (motion corrected) and corrected for slice timing. A mean functional image volume was constructed for each subject per run from the realigned image volumes. These mean images were coregistered with the high-resolution structural image and then segmented for normalization with affine registration followed by nonlinear transformation (Ashburner and Friston, 1997). The normalization parameters determined for the structure volume were then applied to the corresponding functional image volumes for each subject. Finally, the images were smoothed with a Gaussian kernel of 8 mm FWHM.

Imaging data modeling. Trial types were separated for go and no-go responses as well as dollar and nickel reward: GS dollar, GS nickel, GE dollar, GE nickel, NGS dollar, NGS nickel, NGE dollar, and NGE nickel (GS, Go success; GE, go error; NGS, no-go success; NGE, no-go error). A statistical analytical design was constructed for each individual subject, using the GLM with the onsets of go or no-go signals convolved with a canonical HRF and with the temporal derivative of the canonical HRF and entered as regressors in the model (Friston et al., 1995). As go and no-go error trials were associated with an RT, a column of RT was entered as a parametric modulator each for GS, GE, and NGE trials in the model. Realignment parameters in all six dimensions were also entered in the model. The data were high-pass filtered (128 s cutoff) to remove low-frequency signal drifts. Serial autocorrelation caused by aliased cardiovascular and respiratory effects was corrected by a first-degree autoregressive model. The GLM estimated the component of variance that could be explained by each of the regressors.

In the first-level analysis, we constructed for each individual subject statistical contrasts required for second-level analyses. To examine how regional brain activities associated with avoidance behavior varied across subjects in relation to AUDIT score, we conducted a whole-brain multiple regression against AUDIT score with age as a covariate. Specifically, we examined the contrasts (NGS > GS) for dollar and nickel trials separately as well as combined in correlation with the AUDIT score (both positively and negatively). To determine whether trait sensitivity could also predict brain activation in these contrasts, we used a separate GLM with SP and SR scores as the regressors of interest and age as the covariate. As SP and SR may both influence brain activations to GS and to NGS, the inclusion of SP and SR in the same model allowed us to partial out the effects of SR on the neural processes supporting behavioral avoidance and vice versa. The results of all regressions were examined with voxel $p<0.001$ in combination with cluster $p<0.05$, corrected for family-wise error of multiple comparisons, according to current reporting standards (Woo et al., 2014; Eklund et al., 2016). All activations were reported in MNI coordinates, and brain regions were identified by reference to an atlas (Duvernoy, 1999).

Mediation analysis. To examine the interrelationships of trait sensitivity, neural activity, and drinking behavior, we conducted mediation analyses using a single-mediator model (MacKinnon et al., 2007). The methods were detailed in our previous work (Ide and Li, 2011; Ide et al., 2014). Briefly, in a mediation analysis, the relation between the independent variable $\mathrm{X}$ and dependent variable $\mathrm{Y}$; that is, $\mathrm{X} \rightarrow \mathrm{Y}$ is tested to determine whether it is significantly mediated by a variable $\mathrm{M}$. The mediation test is performed using the following three regression equations:

$$
\begin{gathered}
\mathrm{Y}=\mathrm{i} 1+\mathrm{cX}+\mathrm{e} 1 \\
\mathrm{Y}=\mathrm{i} 2+\mathrm{c}^{\prime} \mathrm{X}+\mathrm{bM}+\mathrm{e} 2 \\
\mathrm{M}=\mathrm{i} 3+\mathrm{aX}+\mathrm{e} 3
\end{gathered}
$$

where $a$ indicates $\mathrm{X} \rightarrow \mathrm{M}, b$ indicates $\mathrm{M} \rightarrow \mathrm{Y}$ (controlling for $\mathrm{X}$ ), $c^{\prime}$ indicates $\mathrm{X} \rightarrow \mathrm{Y}$ (controlling for $\mathrm{M}$ ), and $c$ indicates $\mathrm{X} \rightarrow \mathrm{Y}$. $a-c$ and $c^{\prime}$ are referred to as "path coefficients" or simply "paths." Variable M is said to be a mediator of connection $\mathrm{X} \rightarrow \mathrm{Y}$, if $\left(c-c^{\prime}\right)$, which is mathematically equivalent to the product of the paths $a \times b$, is significantly different from zero (MacKinnon et al., 2007). If $\left(c-c^{\prime}\right)$ is different from zero and the paths $a$ and $b$ are significant, one concludes that $\mathrm{X} \rightarrow \mathrm{Y}$ is mediated by $M$. In addition, if path $c^{\prime}$ is not significant, there is no direct connection from $\mathrm{X}$ to $\mathrm{Y}$ and thus $\mathrm{X} \rightarrow \mathrm{Y}$ is completely mediated by $\mathrm{M}$. Note that path $b$ indicates $\mathrm{M} \rightarrow \mathrm{Y}$, controlling for $\mathrm{X}$, and should not be confused with the correlation coefficient between $\mathrm{Y}$ and M. Significant correlations between $\mathrm{X}$ and $\mathrm{Y}$ and between $\mathrm{X}$ and $\mathrm{M}$ are required for one to perform the mediation test. The analysis was performed with package Lavaan (Rosseel, 2012) in R (https://www.r-project.org). To test the significance of the mediation effect, we used the bootstrapping method (Preacher and Hayes, 2004) as it is generally considered advantageous to the Sobel test (MacKinnon et al., 2007).

Specifically, we evaluated the interrelationships between AUDIT score, SP score, and neural activity of NGS dollar $>$ GS dollar (see Results). For neural activity, we extracted the parameter estimates ( $\beta$ values) from the posterior cingulate cortex (PCC). We considered all six models (see Fig. 4D). In Model 1, where SP served as the independent variable (X), PCC activity as the dependent variable (Y), and AUDIT as the mediator (M), SP contributed to AUDIT and, in turn, PCC activity: $\mathrm{SP} \rightarrow$ AUDIT $\rightarrow$ PCC. In Model 2, AUDIT, PCC activity, and SP served as $\mathrm{X}, \mathrm{Y}$, and $\mathrm{M}$, respectively. In Model 3, SP, AUDIT, and PCC activity served as X, Y, and M, respectively. In Model 4, AUDIT, SP, and PCC activity served as X, Y, and M, respectively. In Model 5, PCC activity, AUDIT, and SP served as X, Y, and M, respectively. Finally, in Model 6, PCC activity, SP, and AUDIT served as X, Y, and M, respectively.

\section{Results}

\section{Behavioral results}

Figure $1 C, D$ shows the correct response rate and $\mathrm{RT}$ across conditions. For correct response rate, a two-way (GS vs NGS $\times$ dollar vs nickel) ANOVA showed a significant main effect of response $\left(F_{(1,69)}=171.15, p<0.001\right)$, reward value $\left(F_{(1,69)}=22.50, p<\right.$ $0.001)$, and response $\times$ reward value interaction $\left(F_{(1,69)}=41.85\right.$, $p<0.001)$. In post hoc analyses, correct response rate was higher in the GS dollar than GS nickel trials $(p<0.001)$. In contrast, correct response rate for NGS dollar trials was significantly lower than NGS nickel $(p<0.001)$.

For RT, 24 of the 70 subjects did not commit any errors in one of the trial types and thus were not included in the analysis. A two-way (GS vs NGE $\times$ dollar vs nickel) ANOVA showed a significant main effect of response $\left(F_{(1,45)}=11.39 p<0.001\right)$ and reward value $\left(F_{(1,45)}=17.54 p<0.001\right)$ but not response $\times$ reward value interaction $\left(F_{(1,45)}=2.43 p=0.12\right)$. RT was significantly faster in the GS dollar compared with GS nickel trials ( $p$ values $<0.001)$. The RT of NGE dollar was significantly faster than that of NGE nickel trials $(p<0.004)$. Together, these findings indicated that reward influenced the behavioral performance in opposite directions for dollar and nickel trials. That is, participants' attention was biased toward directional response to the dollar reward.

We next examined the relationship among personality traits (i.e., SP and SR scores), drinking behavior (i.e., AUDIT score), and task performance by conducting linear regressions with age as a covariate. SP $(r=0.30, p=0.01)$, but not SR $(r=0.16, p=$ 0.18 ), was positively correlated with AUDIT score (Fig. 2). SP $(r=0.27, p=0.024)$, but not SR $(r=0.10, p=0.40)$, remained significantly correlated with AUDIT score when SP and SR scores as well as age were included in the same model. Neither SR nor SP was significantly correlated with any of the behavioral measures ( $p$ values $>0.06$ ). AUDIT score showed a trend positive correlation with the rate of NGS dollar trials $(p=0.09)$. 
A

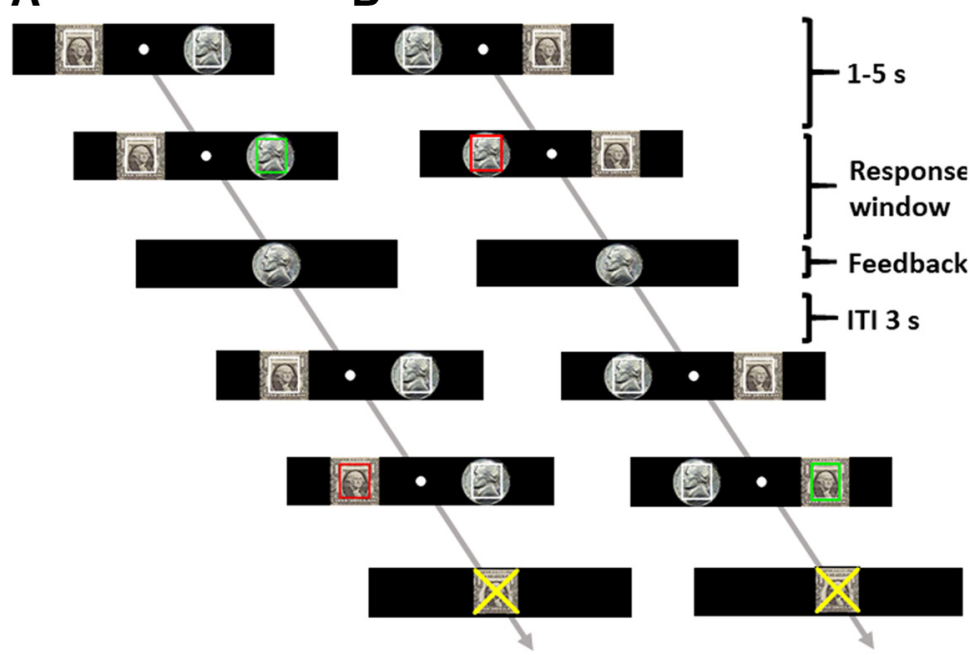

C

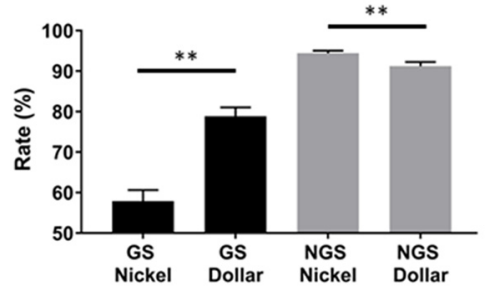

D

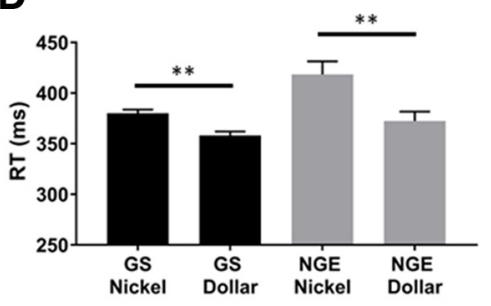

Figure 1. Behavioral task and results. Participants performed a GNG task with the dollar reward on the left $(\boldsymbol{A})$ or on the right $(\boldsymbol{B})$, with the order counterbalanced across subjects. $A$, A successful go trial and failed no-go trial. $B$, A successful no-go and failed go trials. Fore-period varied from 1 to $5 \mathrm{~s}$. Response window for go trials was titrated with data obtained from a prescan session to $\sim 85 \%$ success. Intertrial interval (ITI) was fixed at $3 \mathrm{~s}$. Behavioral results (mean $\pm \mathrm{SE}$ ) showed the correct rate $(\boldsymbol{C})$ and RT $(\boldsymbol{D})$ across trial types. Correct rate was significantly higher for dollar than nickel go trials. The opposite pattern was observed for no-go trials. GS nickel trials showed slower RT than GS dollar trials. NGE nickel trials showed slower RT than NGE dollar trials. ${ }^{* *} p \leq 0.001$.
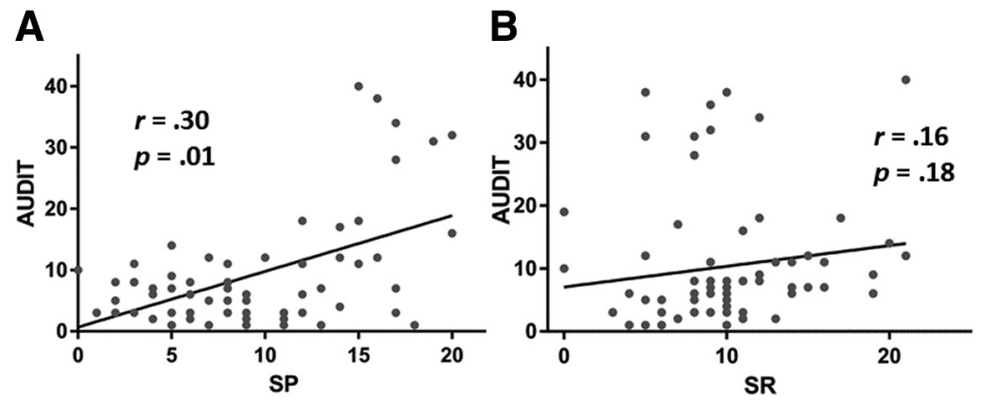

Figure 2. Pearson correlations show the relationship between personality traits and problem drinking across all subjects. Each data point represents one subject. AUDIT score was positively correlated with SP $(\boldsymbol{A})$ but not SR $(\boldsymbol{B})$.

\section{Imaging results}

AUDIT score and no-go versus go

We first examined how AUDIT score modulated brain activation to inhibition of action versus action in the dollar trials (i.e., NGS dollar - GS dollar), controlling for age in a whole-brain regression. AUDIT score showed a significant positive correlation with activity of the PCC and right middle frontal gyrus (Fig. 3A; Table 1). AUDIT score was not significantly correlated with regional responses to inhibition of action for nickel trials (i.e., NGS nickel - GS nickel) or for dollar and nickel trials combined. We also examined whether AUDIT score predicted brain activation to action (GS) > inhibition of action (NGS). No suprathreshold clusters were found for the dollar or nickel trials examined separately or in combination.
SP score, SR score, and no-go versus go dollar

For the dollar trials, SP score was positively correlated with activity during NGS > GS in the PCC, left insula, right thalamus/parahippocampal gyrus, and in a cluster comprising voxels in the bilateral precentral gyrus, postcentral gyrus, and paracentral lobule (Fig. 3B; Table 1). No activations showed a negative correlation with SP score. No significant activations in correlation with SP were observed in either direction for the nickel trials alone or dollar and nickel trials combined. For the dollar or nickel trials examined together or separately, no clusters showed a significant correlation between the contrast GS > NGS and SR score in either direction.

Regional activities modulated by both SP and AUDIT and mediation analysis As SP and AUDIT scores both modulated the PCC activity from the NGS dollar $>$ GS dollar contrast (Fig. 4A), we conducted a mediation analysis to characterize the interrelationship between PCC activity, SP, and AUDIT scores. We first extracted for each participant the parameter estimates ( $\beta$ contrast) of NGS dollar $>$ GS dollar for the PCC. PCC activity was significantly correlated with both AUDIT (Fig. 4B) and SP (Fig. 4C) scores as expected.

As linear regressions showed pairwise correlations between AUDIT score, SP score, and neural activity from the overlapping voxels in the PCC, we examined their interrelationships in a mediation analysis. We tested all six models (Fig. 4D; Table 2). In Model 1, SP contributed to AUDIT, which, in turn, contributed to PCC activity: $\mathrm{SP} \rightarrow$ AUDIT $\rightarrow$ PCC activity. That is, SP and PCC activity served as the independent and dependent variable, respectively, whereas AUDIT served as the mediator. The model was not significant (mediation effect, $p=0.065$ ). In Model 2 (AUDIT $\rightarrow$ SP $\rightarrow$ PCC activity), there was no mediation effect $(p=0.11)$. In Model 3 ( $\mathrm{SP} \rightarrow$ PCC activity $\rightarrow$ AUDIT), PCC activity significantly mediated the effect of SP on AUDIT scores (mediation effect or $c-c^{\prime}$ $=0.35, p=0.014,95 \% \mathrm{CI}=[0.13,0.72]$; highlighted in yellow, left). Specifically, the path coefficient $c$ (i.e., SP $\rightarrow$ AUDIT before accounting for the mediating effect of PCC activity) was significant $(p=0.03)$, and the path coefficient $c^{\prime}$ (i.e., after accounting for the mediating effect) was not significant $(p=0.45)$. Thus, the neural activity fully mediated the relationship between SP and AUDIT scores. In Model 4 (AUDIT $\rightarrow$ PCC activity $\rightarrow$ SP), PCC activity significantly mediated the effect of AUDIT on SP scores (mediation effect or $c-c^{\prime}=0.09, p=0.005,95 \% \mathrm{CI}=[0.04$, $0.17]$; highlighted in yellow, right). The path coefficient $c$ (i.e., AUDIT $\rightarrow$ SP before accounting for the mediating effect of PCC 

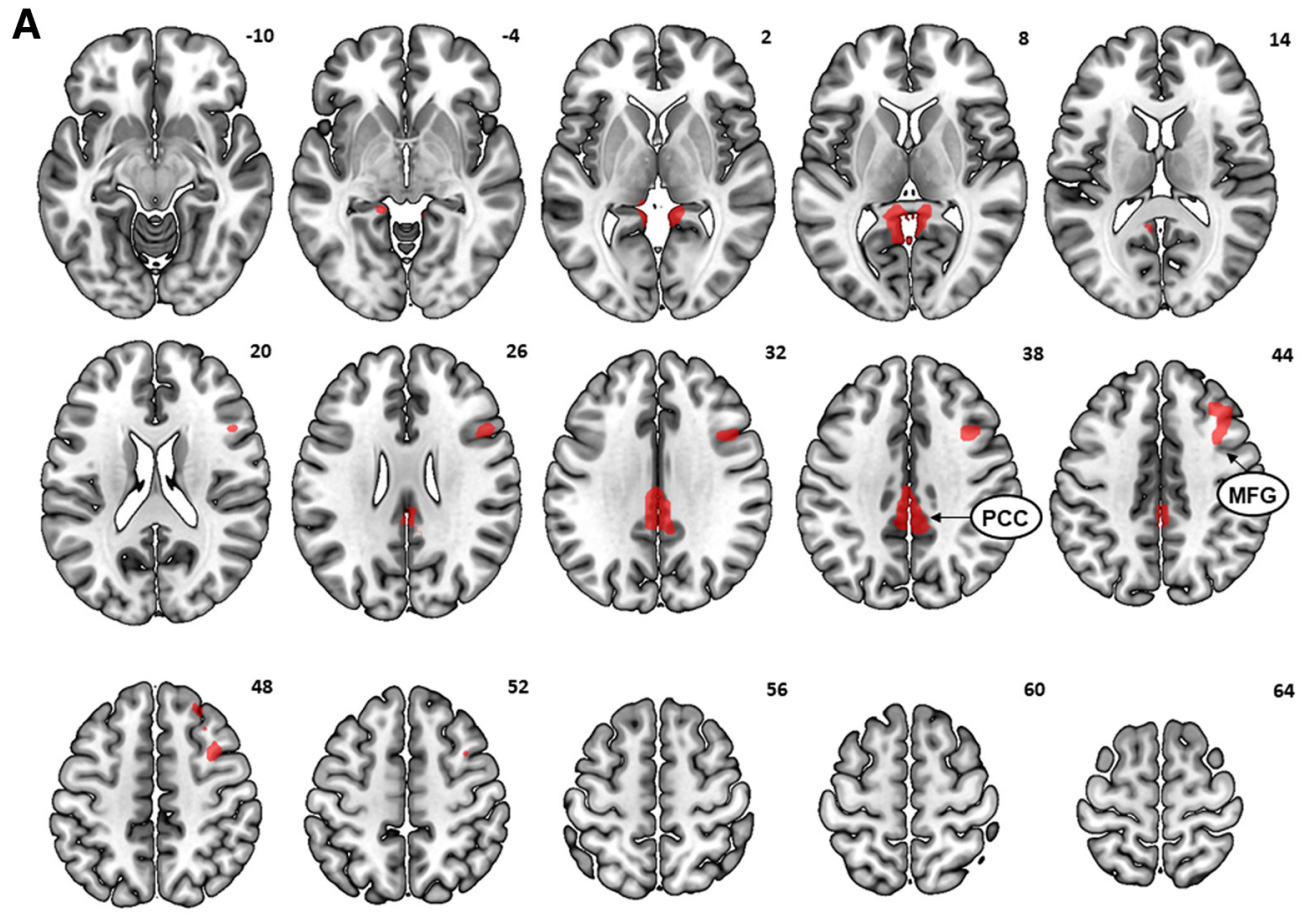

B
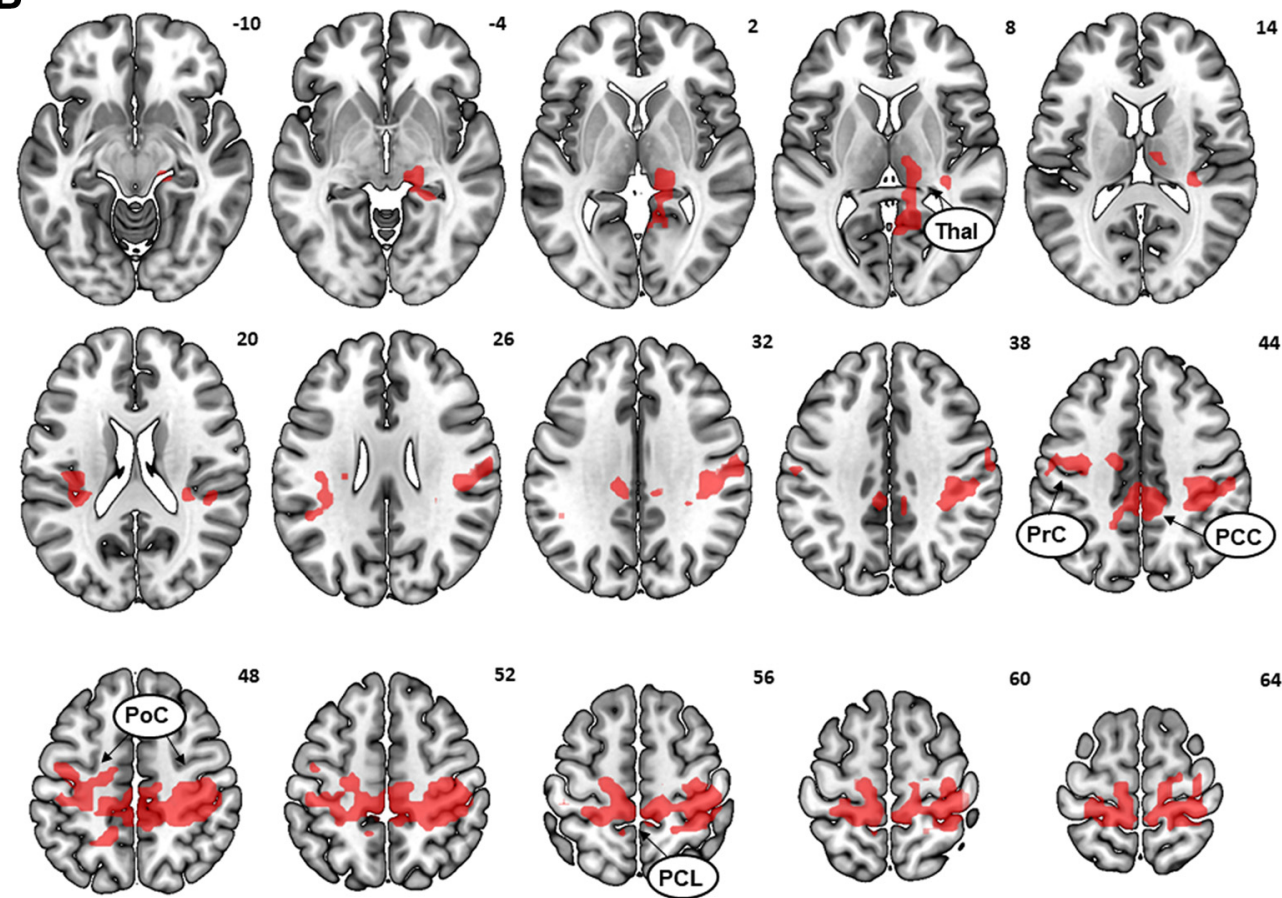

60

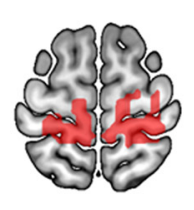

Figure 3. $\quad \boldsymbol{A}$, AUDIT score positively modulated activity during inhibition of action in the dollar trials (NGS_dollar $>$ GS_dollar) in the PCC and right middle frontal gyrus (MFG). $B$, SP score positively modulated activity during inhibition of action in dollar trials in the $\mathrm{PCC}$, left insula (Ins), bilateral precentral gyrus (PrC), postcentral gyrus (PoC), paracentral lobule (PCL), and right thalamus/parahippocampal gyrus (Thal/PHG).

activity) was significant $(p=0.04)$, and the path coefficient $c^{\prime}$ (i.e., after accounting for the mediating effect) was not significant $(p=0.46)$. Thus, the neural activity fully mediated the relationship between AUDIT and SP scores. Finally, neither Model 5 (PCC activity $\rightarrow$ SP $\rightarrow$ AUDIT) nor Model 6, (PCC activity $\rightarrow$ AUDIT $\rightarrow$ SP) produced a significant mediation effect ( $p$ values $>0.46$ ). To control for multiple model testing, we applied a correction for false discovery rate (Benjamini and Hochberg, 1995; Cribbie, 2007). Both Model $3(p=0.042)$ and Model 4 $(p=0.03)$ remained significant after correction. In sum, PCC activity completely and bidirectionally mediated the correlation between SP and AUDIT scores.

As the AUDIT scores did not show a normal distribution $(p<$ 0.001, Shapiro-Wilk test), we applied Box-Cox transformation ( $\lambda=0.5$, square root transformation) to the data, which reduced but did not correct the skewness ( $p=0.002$ ). We next conducted the mediation analysis with the transformed data, which produced a similar pattern of findings: both Model $3(p=0.017)$ and Model $4(p=0.006)$ showed significant mediation effect, whereas Model $1(p=0.104), \operatorname{Model} 2(p=0.113), \operatorname{Model} 5$ ( $p=$ 
Table 1. AUDIT and SP modulation of activation to inhibition of action ${ }^{a}$

\begin{tabular}{|c|c|c|c|c|c|c|}
\hline & \multirow[b]{2}{*}{ Region } & \multicolumn{3}{|c|}{ MNI coordinates (mm) } & \multirow{2}{*}{$\begin{array}{l}\text { Voxel } \\
T\end{array}$} & \multirow{2}{*}{$\begin{array}{l}\text { Cluster } \\
k\end{array}$} \\
\hline & & $x$ & $y$ & $z$ & & \\
\hline \multicolumn{7}{|c|}{ AUDIT } \\
\hline & \multirow[t]{4}{*}{$\mathrm{PCC}$} & 0 & -34 & 34 & 4.60 & 187 \\
\hline & & -3 & -25 & 34 & 4.46 & - \\
\hline & & -6 & -49 & 7 & 4.33 & 193 \\
\hline & & -6 & -40 & 1 & 4.22 & - \\
\hline & \multirow[t]{3}{*}{ Middle frontal gyrus } & 36 & 14 & 40 & 4.23 & 157 \\
\hline & & 36 & 8 & 49 & 4.19 & - \\
\hline & & 45 & 14 & 31 & - & - \\
\hline \multicolumn{7}{|l|}{ SP } \\
\hline & PCC & 6 & -37 & 46 & 5.11 & 2985 \\
\hline & \multirow[t]{3}{*}{ Precentral gyrus } & 33 & -25 & 46 & 4.72 & - \\
\hline & & 33 & -34 & 64 & 5.01 & - \\
\hline & & -12 & -28 & -55 & 4.65 & - \\
\hline & \multirow[t]{2}{*}{ Postcentral gyrus } & 18 & -40 & 70 & 4.81 & - \\
\hline & & -18 & -40 & 70 & 3.89 & - \\
\hline & Paracentral lobule & -6 & -40 & 67 & 3.77 & - \\
\hline & \multirow[t]{2}{*}{ Insula } & -30 & 14 & -8 & 3.99 & 311 \\
\hline & & -36 & -19 & -8 & 3.78 & - \\
\hline & Thalamus/PHG & 12 & -18 & 10 & 3.73 & 289 \\
\hline
\end{tabular}

${ }^{a}$ PHG, Parahippocampal gyrus.

$0.552)$, and Model 6 ( $p=0.536)$ did not. It is worth noting that the Pearson's correlation is robust against the violation of the normality assumption (Havlicek and Peterson, 1976; Norman, $2010)$, especially with a large sample size $(n>10)$ (Bishara and Hittner, 2012), as in the case of the current study.

\section{Sex differences}

In an exploratory analysis, we examined the female $(n=36)$ and male $(n=34)$ participants separately. There was a significant correlation between AUDIT and SP scores, controlling for age, in the female $(r=0.56, p<0.001)$ but not male $(p=0.41)$ group. The multiple regressions of imaging data did not reveal a significant correlation between NGS dollar $>$ GS dollar contrast with either SP or AUDIT score in either group at the corrected threshold. At a lower threshold (voxel-level $p=0.005$ uncorrected), both groups showed a correlation between AUDIT/SP score and PCC activation and a relatively similar patterns of whole-brain correlation maps between the two groups.

\section{Discussion}

The current findings showed that problem drinking, as quantified by the AUDIT, was related to trait SP and brain activity during motivated avoidance. Both SP and AUDIT scores were positively correlated with activity in the PCC during incentivized inhibition of action. Thus, the PCC may represent a shared neutral substrate to support avoidance behavior in response to both the influence of SP and to problem drinking as a coping motive. Mediation models further suggested that PCC activity completely and bidirectionally mediated the relationship between SP and AUDIT scores. That is, heightened SP enhanced the neural activities of avoidance, which contributed to alcohol misuse, and alcohol misuse may have also promoted an avoidance strategy that in turn exacerbated negative affect.

\section{SP and problem drinking}

Traits measuring response to punishment, including the Behavioral Inhibition Scale, have been consistently associated with alcohol misuse. Behavioral Inhibition Scale score was positively correlated with alcohol consumption in large samples of young adults (Stewart and Devine, 2000; Stewart et al., 2002; Kuntsche et al., 2008) and adolescents (Hasking, 2006). Here, we confirmed that nondependent drinkers with elevated SP exhibited greater severity in problem alcohol use. Punishment-sensitive individuals manage aversive emotions by avoidance, using alcohol as an ineffective coping strategy. Drinking leads to more problems, exacerbating negative affect (Cooper et al., 1995). Thus, the impact of SP on problem drinking is mediated by behavioral avoidance.

In support, we identified PCC activity during inhibition of action as a neural correlate of avoidance and a mediator of the relationship between SP and AUDIT scores. Corroborated evidence from previous work shows that alexithymic individuals who reported high SP adopted coping motives that led to hazardous drinking (Lyvers et al., 2012b). Other studies have also found that negative affect predicted the use of alcohol in nondependent adult drinkers (Peirce et al., 2000; Stewart et al., 2002) and the use of other substances in adolescents (Wills et al., 1999), all with avoidance coping as a mediator. It is worth noting that PCC activity mediated the relationship between SP and AUDIT scores bidirectionally. Thus, the PCC appeared to support not only the effects of negative affect on problem drinking but also the impacts of drinking on negative affect, in keeping with the drinking behavior posited by the Motivational Model of Alcohol Use (Cox and Klinger, 1988; Cooper et al., 1995).

\section{Posterior cingulate cortex and behavioral avoidance}

With its anatomical connections to both the limbic and frontoparietal systems, the PCC is positioned to support behavioral avoidance (Carmichael and Price, 1995; Morecraft and Tanji, 2009). In animal studies, the PCC was implicated in behavioral avoidance during water maze navigation (Riekkinen et al., 1995) and learning to avert foot shock (Vogt et al., 1991; Duvel et al., 2001). PCC neurons also increased activity to the inhibition of no-longer rewarded behavior following changes in reward contingencies (Hayden et al., 2008; Pearson et al., 2011). Synaptic plasticity in the PCC was involved in memory consolidation for avoidance (Pereira et al., 2002), and muscimol inactivation of the PCC immediately after training impaired memory and compromised avoidance behavior (Souza et al., 2002).

In humans, the PCC supports defensive behavior in response to fear and threats (McNaughton and Corr, 2004). A metaanalysis of imaging studies showed increases in PCC activation to pain processing (Nielsen et al., 2005). Electrophysiological work also implicated the PCC in the response to pain and negative affect (Vogt, 2005; Benuzzi et al., 2008; Shackman et al., 2011). EEG revealed reduced alpha-band activity in the PCC before the onset of stimuli when participants viewed images of needle pricks (Höfle et al., 2013). Further, the PCC has been shown to contribute to the inhibition of prepotent motor actions (Leech and Sharp, 2014). A recent study examining escape decisions showed that protracted escape decisions were associated with "cognitive fear" circuits that included the PCC (Qi et al., 2018). The current findings extend the literature by highlighting the role of the PCC in individual differences related to avoidance trait and behavior.

The choice of the GNG paradigm is supported by previous evidence that behavioral avoidance in drinkers, as also in the case of the no-go response to avoid punishment, involves both motivational and executive processes. For instance, avoidance behavior in coping drinkers is associated with enhanced executive control (Koch et al., 2008) and biased allocation of attentional resources away from negative outcomes/stimuli (Mogg et al., 2000; Shane and Peterson, 2004). These reports are consistent with the Motivational Model of Alcohol Use, which posits that coping drinkers seek the stimulating effects of alcohol to divert 

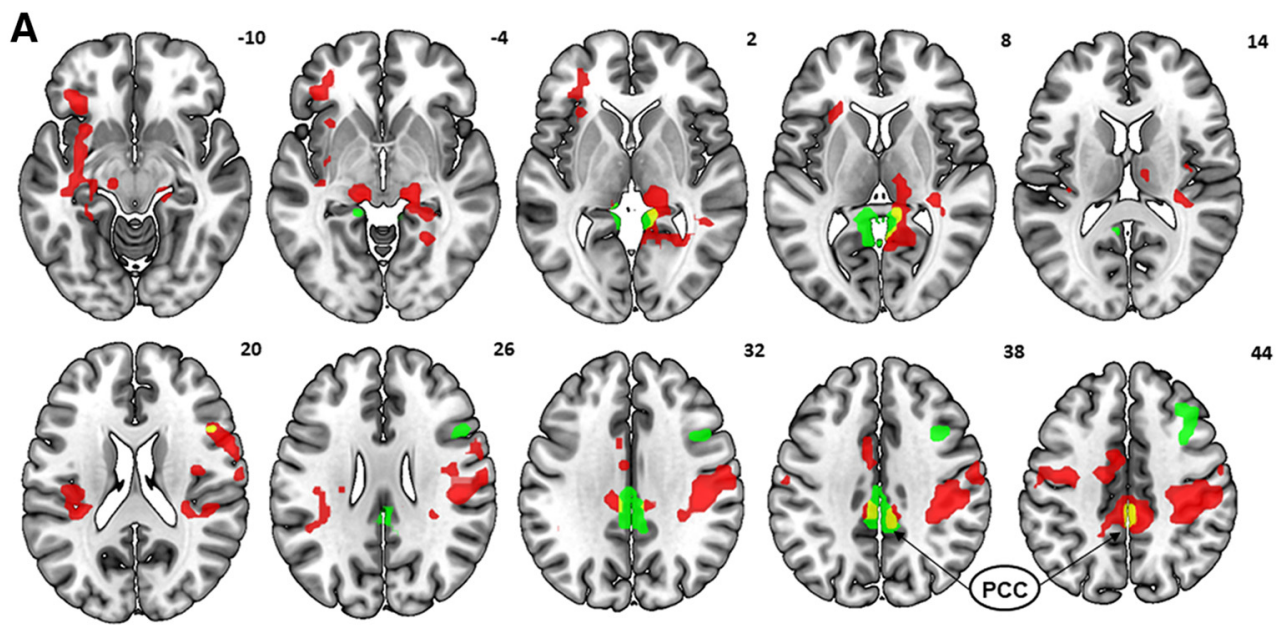

B

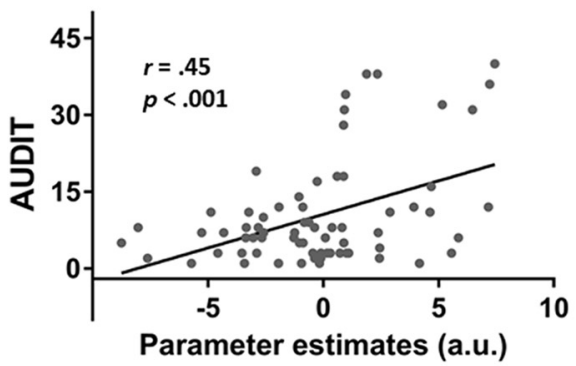

D

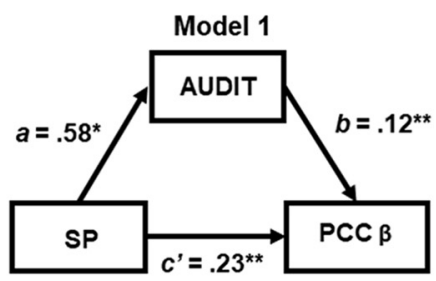

Mediation effect $=.07$ $p=.065$

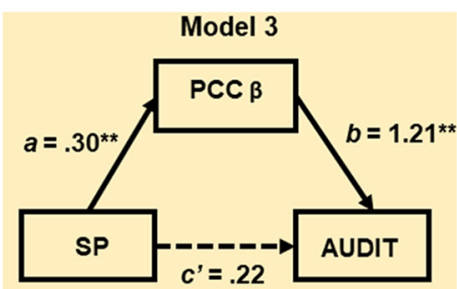

Mediation effect $=.36$

$$
p=.014
$$

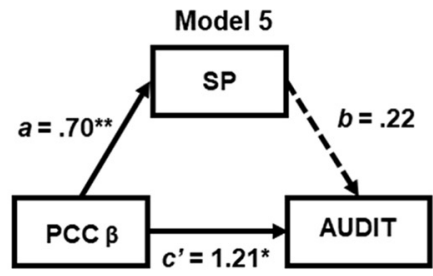

Mediation effect $=.15$

$$
p=.49
$$

C
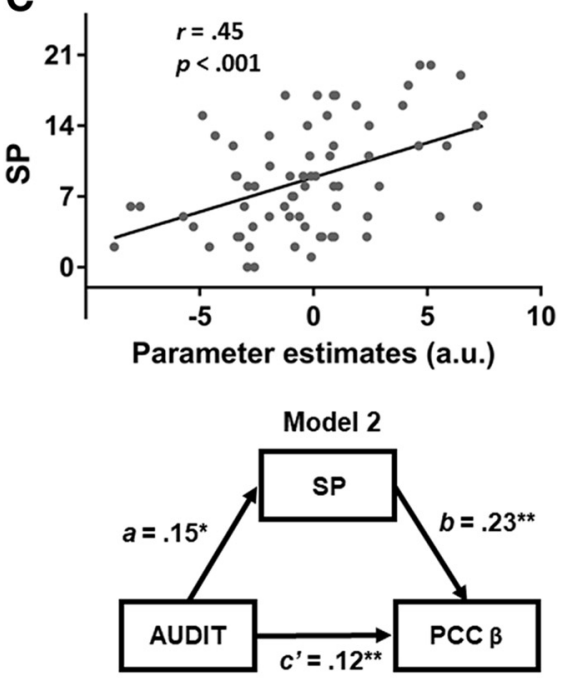

Mediation effect $=.04$

$p=.11$

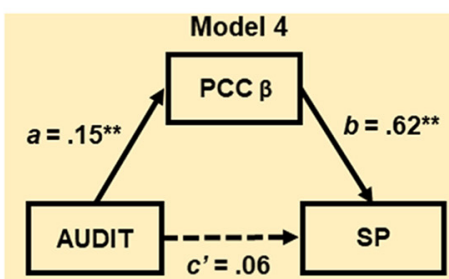

Mediation effect $=.09$

$p=.005$

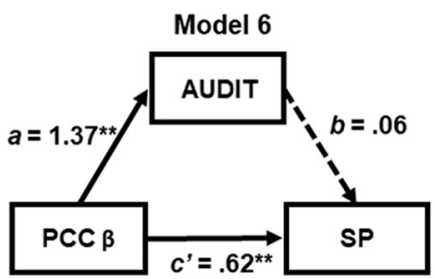

Mediation effect $=.08$

$$
p=.46
$$

Figure 4. A, Overlapping voxels (yellow) in the PCC were identified from two contrasts involving AUDIT (green) and SP (red) correlations with activity for NGS dollar $>$ GS dollar. PCC activity was positively correlated with (B) AUDIT and (C) SP scores across all subjects. D, Mediation analysis. Model 1: SP $\rightarrow$ AUDIT $\rightarrow$ PCC activity; Model 2: AUDIT $\rightarrow$ SP $\rightarrow$ PCC activity; Model: 3 SP $\rightarrow$ PCC activity $\rightarrow$ AUDIT; Model 4: AUDIT $\rightarrow$ PCC activity $\rightarrow$ SP; Model 5: PCC activity $\rightarrow$ SP $\rightarrow$ AUDIT; and Model 6: PCC activity $\rightarrow$ AUDIT $\rightarrow$ SP. Both Model 3 and Model 4 showed a significant and complete mediation effect. ${ }^{*} p<.05,{ }^{* *} p<.01$. 
Table 2. Mediation of AUDIT, SP, and PCC activity during inhibition of action

\begin{tabular}{|c|c|c|c|c|c|}
\hline & $\begin{array}{l}\text { Path } a \\
(X \rightarrow M)\end{array}$ & $\begin{array}{l}\text { Path } b \\
(M \rightarrow Y)\end{array}$ & $\begin{array}{l}\text { Path } c \\
(X \rightarrow Y)\end{array}$ & $\begin{array}{l}\text { Path } c^{\prime} \\
(X \rightarrow Y)\end{array}$ & $\begin{array}{l}\text { Mediation } \\
\text { path }\left(c-c^{\prime}\right)\end{array}$ \\
\hline \multicolumn{6}{|c|}{ Model $1: X(S P) \rightarrow Y$ (PCC activity) mediated by $M$ (AUDIT) } \\
\hline$\beta$ & 0.58 & 0.12 & 0.30 & 0.23 & 0.07 \\
\hline$p$ & 0.033 & 0.001 & 0.001 & 0.001 & 0.065 \\
\hline \multicolumn{6}{|c|}{ Model 2: $X$ (AUDIT) $\rightarrow Y(P C C$ activity) mediated by $M$ (SP) } \\
\hline$\beta$ & 0.15 & 0.23 & 0.15 & 0.11 & 0.04 \\
\hline$p$ & 0.040 & 0.001 & 0.001 & 0.001 & 0.105 \\
\hline \multicolumn{6}{|c|}{ Model 3: $X(S P) \rightarrow Y$ (AUDIT) mediated by $M$ (PCC activity) } \\
\hline$\beta$ & 0.30 & 1.21 & 0.58 & 0.22 & 0.36 \\
\hline$p$ & 0.001 & 0.004 & 0.033 & 0.448 & 0.014 \\
\hline \multicolumn{6}{|c|}{ Model 4: $X$ (AUDIT) $\rightarrow Y(S P)$ mediated by $M(P C C$ activity) } \\
\hline$\beta$ & 0.15 & 0.62 & 0.15 & 0.06 & 0.09 \\
\hline$p$ & 0.001 & 0.001 & 0.040 & 0.456 & 0.005 \\
\hline \multicolumn{6}{|c|}{ Model 5: $X$ (PCC activity) $\rightarrow Y$ (AUDIT) mediated by $M$ (SP) } \\
\hline$\beta$ & 0.7 & 0.22 & 1.37 & 1.21 & 0.15 \\
\hline$p$ & 0.001 & 0.448 & 0.001 & 0.004 & 0.486 \\
\hline \multicolumn{6}{|c|}{ Model 6: $X$ (PCC activity) $\rightarrow Y(S P)$ mediated by $M$ (AUDIT) } \\
\hline$\beta$ & 1.37 & 0.06 & 0.7 & 0.62 & 0.08 \\
\hline$p$ & 0.001 & 0.456 & 0.001 & 0.001 & 0.458 \\
\hline
\end{tabular}

their attention from negative affect (Cooney et al., 1997; Bacon and Ham, 2010; Adams et al., 2012). Further, drinking to reduce aversive emotion is a regulation strategy that actively engages perception, memory, and inhibition (Cox and Klinger, 1988), all of which involve executive function. Thus, avoidance behavior likely depends on the integration of punishment sensitivity and executive control. Together, the current work shows that avoidance behavior in coping drinkers involves response inhibition and punishment sensitivity, both of which are associated with PCC activity and alcohol misuse.

\section{A broader role of the PCC in alcohol misuse, affective processing, and mood disorders}

The PCC has also been extensively implicated in other cognitive and affective processes critical to alcohol and drug use. The PCC showed higher activation during exposure to drug and alcohol compared with neutral cues (Tapert et al., 2003; Schacht et al., 2013), and such activation was positively correlated with alcohol consumption (Tapert et al., 2003; Bragulat et al., 2008) in hazardous drinkers. Enhanced PCC activation to drug versus control imagery was not only associated with craving (Garavan et al., 2000; Kilts et al., 2004) but also relapse likelihood (Kosten et al., 2006). Patients with alcohol use disorders performing a GNG task, which involved alcohol-related and neutral no-go trials showed craving in association with conflictrelated enhancement of the N2 component localized in the PCC (Stein et al., 2018). Further, gray matter volume of the PCC was lower in dependent drinkers than in healthy controls (Chanraud et al., 2009; Mashhoon et al., 2014; Mackey et al., 2018) and predictive of shorter time to relapse to alcohol use (Rando et al., 2011).

Alcohol misuse is frequently comorbid with anxiety and depression. Clinical studies have shown altered PCC functions in patients with mood disorders, including decreases in cerebral glucose metabolism (Wu et al., 1991; Mayberg et al., 1997) and activation during emotional processing (Zhao et al., 2007), relative to healthy controls. Depression patients who responded to antidepressants showed recovery in PCC glucose metabolism, whereas nonresponders did not (Mayberg et al., 1997). Individuals with post-traumatic stress disorder, compared with controls, exhibited reduced PCC resting-state connectivity with the hip- pocampus, and the degree of this reduction was positively associated with avoidance symptoms (Miller et al., 2017). In a decision-making task, youth with a history of substance abuse, relative to those without, demonstrated increased, rather than decreased, differential correlation between PCC response and prediction error to reward versus punishment, suggesting a failure to represent expected value during the avoidance of suboptimal choices (White et al., 2016).

Together, these studies support a broader role of the PCC in alcohol misuse and comorbid emotional disorders. Future studies are warranted to investigate how the PCC integrates these diverse cognitive and affective processes to influence problem drinking.

\section{Reward sensitivity and alcohol misuse}

The current results support a significant relationship between problem drinking and SP, but not to SR, seemingly at odds with the literature that heightened SR is associated with increased alcohol use (Loxton and Dawe, 2007; Pardo et al., 2007; Gullo et al., 2010). However, the earlier studies focused on younger individuals (average age of $\sim 22$ years) whose drinking behavior likely differed from the current sample (mean age: 36 years; range: 21-74 years). Young and older people exhibit different drinking motives, with the former more frequently reporting enhancement motivation as the primary reason for alcohol use (Kuntsche et al., 2005) to seek fun and promote social life (Senchak et al., 1998; Lyvers et al., 2012a). Research in adolescence similarly found enhancement, rather than coping, motive to be a better predictor of alcohol misuse (Bradizza et al., 1999). In contrast, coping, but not enhancement, motives were linked with heavier alcohol consumption (Gilson et al., 2013) and drinking problems (Moos et al., 1990) in older individuals. As SR and SP are related to enhancement and coping strategies, respectively (Colder and O'Connor, 2002; Kuntsche et al., 2006; Adams et al., 2012), it stands to reason that drinking is significantly associated with SR in youth but less so in older individuals. Indeed, after removing participants over the age of 30, SR and AUDIT did show a positive correlation in the young adults $(r=0.35, p<0.05, n=33)$ in the current cohort. This observation highlights the importance of considering age when examining the relationship of personality traits and drinking behavior.

\section{Limitations and conclusions}

Several limitations are considered. First, other than a trend correlation between NGS rate of dollar trials and the AUDIT score, behavioral outcomes in the GNG task were not significantly correlated with the AUDIT, SR, or SP scores. The reward GNG task thus did not provide behavioral analogs that captured the avoidance trait and severity of alcohol misuse. Second, as causality cannot be inferred from correlation, we must treat the results of mediation analyses with caution. Longitudinal studies are needed to examine whether PCC activity in conjunction with SP predicts changes in drinking behavior. Finally, previous research has suggested important cerebral structural (Rosenbloom et al., 2003) and functional (Mann et al., 2001) differences in dependent and nondependent drinkers. Thus, it remains to be seen whether the current findings would generalize to dependent drinkers.

Despite these limitations, our results suggest a distinct role of the PCC in the interrelated neural processes of avoidance, trait $\mathrm{SP}$, and problem drinking. Substantiating the theory of motivation of alcohol use, these findings advance our understanding of 
the etiologies of alcohol misuse and may provide a biomarker for individualized interventions.

\section{References}

Adams ZW, Kaiser AJ, Lynam DR, Charnigo RJ, Milich R (2012) Drinking motives as mediators of the impulsivity-substance use relation: pathways for negative urgency, lack of premeditation, and sensation-seeking. Addict Behav 37:848-855.

Addolorato G, Leggio L, Abenavoli L, Gasbarrini G (2005) Neurobiochemical and clinical aspects of craving in alcohol addiction: a review. Addict Behav 30:1209-1224.

Ashburner J, Friston K (1997) The role of registration and spatial normalisation in detecting activations in functional imaging. Clin MRI Dev MR 7:26-28.

Babor TF, Higgin-Biddle JC, Saunders JB, Monteiro MG (2001) The alcohol use disorders identification test: Guidelines for use in primary care. Geneva: World Health Organization. Available at https://apps.who.int/iris/ handle/ 10665/67205.

Bacon AK, Ham LS (2010) Attention to social threat as a vulnerability to the development of comorbid social anxiety disorder and alcohol use disorders: an avoidance-coping cognitive model. Addict Behav 35:925-939.

Benjamini Y, Hochberg Y (1995) Controlling the false discovery rate: a practical and powerful approach to multiple testing. J R Stat Soc Ser B 57:289-300.

Benuzzi F, Lui F, Duzzi D, Nichelli PF, Porro CA (2008) Does it look painful or disgusting? Ask your parietal and cingulate cortex. J Neurosci 28:923-931.

Bishara AJ, Hittner JB (2012) Testing the significance of a correlation with nonnormal data: comparison of Pearson, Spearman, transformation, and resampling approaches. Psychol Methods 17:399-417.

Bobova L, Finn PR, Rickert ME, Lucas J (2009) Disinhibitory psychopathology and delay discounting in alcohol dependence: personality and cognitive correlates. Exp Clin Psychopharmacol 17:51-61.

Bradizza CM, Reifman A, Barnes GM (1999) Social and coping reasons for drinking: predicting alcohol misuse in adolescents. J Stud Alcohol 60:491499.

Bragulat V, Dzemidzic M, Talavage T, Davidson D, O'Connor SJ, Kareken DA (2008) Alcohol sensitizes cerebral responses to the odors of alcoholic drinks: an fMRI study. Alcohol Clin Exp Res 32:1124-1134.

Carmichael ST, Price JL (1995) Limbic connections of the orbital and medial prefrontal cortex in macaque monkeys. J Comp Neurol 363515:641.

Chanraud S, Leroy C, Martelli C, Kostogianni N, Delain F, Aubin HJ, Reynaud M, Martinot JL (2009) Episodic memory in detoxified alcoholics: contribution of grey matter microstructure alteration. PLoS One 4:e6786.

Colder CR, O'Connor R (2002) Attention biases and disinhibited behavior as predictors of alcohol use and enhancement reasons for drinking. Psychol Addict Behav 16:325-332.

Cooney NL, Litt MD, Morse PA, Bauer LO, Gaupp L (1997) Alcohol cue reactivity, negative-mood reactivity, and relapse in treated alcoholic men. J Abnorm Psychol 106:243-250.

Cooper ML (1994) Motivations for alcohol use among adolescents: development and validation of a four-factor model. Psychol Assess 6:117-128.

Cooper ML, Frone MR, Russell M, Mudar P (1995) Drinking to regulate positive and negative emotions: a motivational model of alcohol use. J Pers Soc Psychol 69:990-1005.

Cox WM, Klinger E (1988) A motivational model of alcohol use. J Abnorm Psychol 97:168-180.

Cribbie RA (2007) Multiplicity control in structural equation modeling. Struct Equ Model A Multidiscip J 14:98-112.

Duvel AD, Smith DM, Talk A, Gabriel M (2001) Medial geniculate, amygdalar and cingulate cortical training-induced neuronal activity during discriminative avoidance learning in rabbits with auditory cortical lesions. J Neurosci 21:3271-3281.

Duvernoy HM (1999) Human brain atlas. Vienna: Springer.

Eklund A, Nichols TE, Knutsson H (2016) Cluster failure: why fMRI inferences for spatial extent have inflated false-positive rates. Proc Natl Acad Sci U S A 113:7900-7905.

Franken IH (2002) Behavioral approach system (BAS) sensitivity predicts alcohol craving. Pers Individ Dif 32:349-355.
Friston KJ, Holmes AP, Poline JB, Grasby PJ, Williams SC, Frackowiak RS, Turner R (1995) Analysis of fMRI time-series revisited. Neuroimage 2:45-53.

Galandra C, Basso G, Cappa S, Canessa N (2018) The alcoholic brain: neural bases of impaired reward-based decision-making in alcohol use disorders. Neurol Sci 39:423-435.

Garavan H, Pankiewicz J, Bloom A, Cho JK, Sperry L, Ross TJ, Salmeron BJ, Risinger R, Kelley D, Stein EA (2000) Cue-induced cocaine craving: neuroanatomical specificity for drug users and drug stimuli. Am J Psychiatry 157:1789-1798.

Gilson KM, Bryant C, Bei B, Komiti A, Jackson H, Judd F (2013) Validation of the drinking motives questionnaire (DMQ) in older adults. Addict Behav 38:2196-2202.

Grau E, Ortet G (1999) Personality traits and alcohol consumption in a sample of non-alcoholic women. Pers Individ Dif 27:1057-1066.

Gullo MJ, Jackson CJ, Dawe S (2010) Impulsivity and reversal learning in hazardous alcohol use. Pers Individ Dif 48:123-127.

Hasking PA (2006) Reinforcement sensitivity, coping, disordered eating and drinking behaviour in adolescents. Pers Individ Dif 40:677-688.

Havlicek LL, Peterson NL (1976) Robustness of the Pearson correlation against violations of assumptions. Percept Mot Skills 43:1319-1334.

Hayden BY, Nair AC, McCoy AN, Platt ML (2008) Posterior cingulate cortex mediates outcome-contingent allocation of behavior. Neuron 60:1925.

Heinrich A, Müller KU, Banaschewski T, Barker GJ, Bokde ALW, Bromberg U, Büchel C, Conrod P, Fauth-Bühler M, Papadopoulos D, Gallinat J, Garavan H, Gowland P, Heinz A, Ittermann B, Mann K, Martinot JL, Paus T, Pausova Z, Smolka M, et al. (2016) Prediction of alcohol drinking in adolescents: personality-traits, behavior, brain responses, and genetic variations in the context of reward sensitivity. Biol Psychol 118:79-87.

Hittner JB, Swickert R (2006) Sensation-seeking and alcohol use: a metaanalytic review. Addict Behav 31:1383-1401.

Höfle M, Pomper U, Hauck M, Engel AK, Senkowski D (2013) Spectral signatures of viewing a needle approaching one's body when anticipating pain. Eur J Neurosci 38:3089-3098.

Holahan CJ, Moos RH, Holahan CK, Cronkite RC, Randall PK (2001) Drinking to cope, emotional distress and alcohol use and abuse: a ten-year model. J Stud Alcohol 62:190-198.

Houben K, Havermans RC, Nederkoorn C, Jansen A (2012) Beer à no-go: learning to stop responding to alcohol cues reduces alcohol intake via reduced affective associations rather than increased response inhibition. Addiction 107:1280-1287.

Ide JS, Li C (2011) A cerebellar thalamic cortical circuit for error-related cognitive control. Neuroimage 54:455-464.

Ide JS, Zhang S, Hu S, Matuskey D, Bednarski SR, Erdman E, Farr OM, Li CS (2014) Gray matter volume correlates of global positive alcohol expectancy in non-dependent adult drinkers. Addict Biol 19:895-906.

Kilts CD, Gross RE, Ely TD, Drexler KP (2004) The neural correlates of cue-induced craving in cocaine-dependent women. Am J Psychiatry 161: 233-241.

King KM, Patock-Peckham JA, Dager AD, Thimm K, Gates JR (2014) On the mismeasurement of impulsivity: trait, behavioral, and neural models in alcohol research among adolescents and young adults. Curr Addict Rep 1:19-32.

Knyazev GG, Slobodskaya HR, Wilson GD (2002) Psychophysiological correlates of behavioural inhibition and activation. Pers Individ Dif 33:647660.

Koch S, Holland RW, van Knippenberg A (2008) Regulating cognitive control through approach-avoidance motor actions. Cognition 109: 133-142.

Koob G, Rassnick S, Heinrichs S, Weiss F (1994) Alcohol, the reward system and dependence. In: Toward a molecular basis of alcohol use and abuse. New York: Springer.

Kosten TR, Scanley BE, Tucker KA, Oliveto A, Prince C, Sinha R, Potenza MN, Skudlarski P, Wexler BE (2006) Cue-induced brain activity changes and relapse in cocaine-dependent patients. Neuropsychopharmacology 31:644-650.

Kreusch F, Quertemont E, Vilenne A, Hansenne M (2014) Alcohol abuse and ERP components in Go/No-go tasks using alcohol-related stimuli: impact of alcohol avoidance. Int J Psychophysiol 94:92-99. 
Kuntsche E, Knibbe R, Gmel G, Engels R (2005) Why do young people drink? A review of drinking motives. Clin Psychol Rev 25:841-861.

Kuntsche E, Knibbe R, Gmel G, Engels R (2006) Who drinks and why? A review of socio-demographic, personality, and contextual issues behind the drinking motives in young people. Addict Behav 31:1844-1857.

Kuntsche E, von Fischer M, Gmel G (2008) Personality factors and alcohol use: a mediator analysis of drinking motives. Pers Individ Dif 45:796-800.

Leech R, Sharp DJ (2014) The role of the posterior cingulate cortex in cognition and disease. Brain 137:12-32.

Loxton NJ, Dawe S (2001) Alcohol abuse and dysfunctional eating in adolescent girls: the influence of individual differences in sensitivity to reward and punishment. Int J Eat Disord 29:455-462.

Loxton NJ, Dawe S (2007) How do dysfunctional eating and hazardous drinking women perform on behavioural measures of reward and punishment sensitivity? Pers Individ Dif 42:1163-1172.

Lyvers M, Duff H, Basch V, Edwards MS (2012a) Rash impulsiveness and reward sensitivity in relation to risky drinking by university students: potential roles of frontal systems. Addict Behav 37:940-946.

Lyvers M, Hasking P, Albrecht B, Thorberg FA (2012b) Alexithymia and alcohol: the roles of punishment sensitivity and drinking motives. Addict Res Theory 20:348-357.

Mackey S, Allgaier N, Chaarani B, Spechler P, Orr C, Bunn J, Allen NB, Alia-Klein N, Batalla A, Blaine S, Brooks S, Caparelli E, Chye YY, Cousijn J, Dagher A, Desrivieres S, Feldstein-Ewing S, Foxe JJ, Goldstein RZ, Goudriaan AE, et al. (2018) Mega-analysis of gray matter volume in substance dependence: general and substance-specific regional effects. Am J Psychiatry 176:119-128.

MacKinnon DP, Fairchild AJ, Fritz MS (2007) Mediation analysis. Annu Rev Psychol 58:593-614.

Mann K, Agartz I, Harper C, Shoaf S, Rawlings RR, Momenan R, Hommer DW, Pfefferbaum A, Sullivan EV, Anton RF, Drobes DJ, George MS, Bares R, Machulla HJ, Mundle G, Reimold M, Heinz A (2001) Neuroimaging in alcoholism: ethanol and brain damage. Alcohol Clin Exp Res 25:104S-109S.

Marlatt GA, Gordon JR (1980) Determinants of relapse: implications for maintenance of behavioral change. In: Behavioral medicine: changing health lifestyles (Davidson PO, ed). New York: Brunner/Mazel.

Mashhoon Y, Czerkawski C, Crowley DJ, Cohen-Gilbert JE, Sneider JT, Silveri MM (2014) Binge alcohol consumption in emerging adults: anterior cingulate cortical "thinness" is associated with alcohol use patterns. Alcohol Clin Exp Res 38:1955-1964.

Mayberg HS, Brannan SK, Mahurin RK, Jerabek PA, Brickman JS, Tekell JL, Silva JA, McGinnis S, Glass TG, Martin CC, Fox PT (1997) Cingulate function in depression. Neuroreport 8:1057-1061.

McNaughton N, Corr PJ (2004) A two-dimensional neuropsychology of defense: fear/anxiety and defensive distance. Neurosci Biobehav Rev 28: 285-305.

Merrill JE, Read JP (2010) Motivational pathways to unique types of alcohol consequences. Psychol Addict Behav 24:705-711.

Miller DR, Hayes SM, Hayes JP, Spielberg JM, Lafleche G, Verfaellie M (2017) Default mode network subsystems are differentially disrupted in posttraumatic stress disorder. Biol Psychiatry Cogn Neurosci Neuroimaging 2:363-371.

Mogg K, Bradley BP, Dixon C, Fisher S, Twelftree H, McWilliams A (2000) Trait anxiety, defensiveness and selective processing of threat. Pers Individ Dif 28:1063-1077.

Moos RH, Brennan PL, Fondacaro MR, Moos BS (1990) Approach and avoidance coping responses among older problem and nonproblem drinkers. Psychol Aging 5:31-40.

Morecraft RJ, Tanji J (2009) Cingulate neurobiology and disease (Vogt BA, ed). New York: Oxford UP.

Newman JP, Schmitt WA (1998) Passive avoidance in psychopathic offenders: a replication and extension. J Abnorm Psychol 107:527-532.

Nielsen FA, Balslev D, Hansen LK (2005) Mining the posterior cingulate: segregation between memory and pain components. Neuroimage 27: $520-532$.

Norman G (2010) Likert scales, levels of measurement and the "laws" of statistics. Adv Health Sci Educ Theory Pract 15:625-632.

Olbrich HM, Valerius G, Paris C, Hagenbuch F, Ebert D, Juengling FD (2006) Brain activation during craving for alcohol measured by positron emission tomography. Aust N Z J Psychiatry 40:171-178.

Pardo Y, Aguilar R, Molinuevo B, Torrubia R (2007) Alcohol use as a be- havioural sign of disinhibition: evidence from J.A. Gray's model of personality. Addict Behav 32:2398-2403.

Pearson JM, Heilbronner SR, Barack DL, Hayden BY, Platt ML (2011) Posterior cingulate cortex: adapting behavior to a changing world. Trends Cogn Sci 15:143-151.

Peirce RS, Frone MR, Russell M, Cooper ML, Mudar P (2000) A longitudinal model of social contact, social support, depression, and alcohol use. Heal Psychol 19:28-38.

Pereira GS, Mello e Souza T, Battastini AM, Izquierdo I, Sarkis JJ, Bonan CD (2002) Effects of inhibitory avoidance training and/or isolated footshock on ectonucleotidase activities in synaptosomes of the anterior and posterior cingulate cortex and the medial precentral area of adult rats. Behav Brain Res 128:121-127.

Preacher KJ, Hayes AF (2004) SPSS and SAS procedures for estimating indirect effects in simple mediation models. Behav Res Methods Instrum Comput 36:717-731.

Qi S, Hassabis D, Sun J, Guo F, Daw N, Mobbs D (2018) How cognitive and reactive fear circuits optimize escape decisions in humans. Proc Natl Acad Sci U S A 115:201712314

Rando K, Hong KI, Bhagwagar Z, Li CS, Bergquist K, Guarnaccia J, Sinha R (2011) Association of frontal and posterior cortical gray matter volume with time to alcohol relapse: a prospective study. Am J Psychiatry 168: 183-192.

Riekkinen P Jr, Kuitunen J, Riekkinen M (1995) Effects of scopolamine infusions into the anterior and posterior cingulate on passive avoidance and water maze navigation. Brain Res 685:46-54.

Rosenbloom M, Sullivan EV, Pfefferbaum A (2003) Using magnetic resonance imaging and diffusion tensor imaging to assess brain damage in alcoholics. Alcohol Res Health 27:146-152.

Rosseel Y (2012) Lavaan: an R package for structural equation modeling and more. J Stat Softw 48:1-36.

Saunders J, Assland O, Babor T, de la Fuente J, Grant M (1993) Development of the alcohol use disorders identification test (AUDIT): WHO collaborative project on early detection of persons with harmful alcohol consumption-II. Addiction 88:701-904.

Schacht JP, Anton RF, Myrick H (2013) Functional neuroimaging studies of alcohol cue reactivity: a quantitative meta-analysis and systematic review. Addict Biol 18:121-133.

Senchak M, Leonard KE, Greene BW (1998) Alcohol use among college students as a function of their typical social drinking context. Psychol Addict Behav 12:62-70

Shackman AJ, Salomons TV, Slagter HA, Fox AS, Winter JJ, Davidson RJ (2011) The integration of negative affect, pain and cognitive control in the cingulate cortex. Nat Rev Neurosci 12:154-167.

Shane MS, Peterson JB (2004) Defensive copers show a deficit in passive avoidance learning on Newman's Go/No-go task: implications for selfdeception and socialization. J Pers 72:939-965.

Souza MM, Mello e Souza T, Vinadé ER, Rodrigues C, Choi HK, Dedavid e Silva TL, Medina JH, Izquierdo I (2002) Effects of posttraining treatments in the posterior cingulate cortex on short- and long-term memory for inhibitory avoidance in rats. Neurobiol Learn Mem 77:202-210.

Stein M, Fey W, Koenig T, Oehy J, Moggi F (2018) Context-specific inhibition is related to craving in alcohol use disorders: a dangerous imbalance. Alcohol Clin Exp Res 42:69-80.

Stewart SH, Devine H (2000) Relations between personality and drinking motives in young adults. Pers Individ Dif 29:495-511.

Stewart SH, Zvolensky MJ, Eifert GH (2002) The relations of anxiety sensitivity, experiential avoidance, and alexithymic coping to young adults' motivations for drinking. Behav Modif 26:274-296.

Tapert SF, Cheung EH, Brown GG, Frank LR, Paulus MP, Schweinsburg AD, Meloy MJ, Brown SA (2003) Neural response to alcohol stimuli in adolescents with alcohol use disorder. Arch Gen Psychiatry 60:727-735.

Tapper K, Baker L, Jiga-Boy G, Haddock G, Maio GR (2015) Sensitivity to reward and punishment: associations with diet, alcohol consumption, and smoking. Pers Individ Dif 72:79-84.

Torrubia R, Ávila C, Moltó J, Caseras X (2001) The sensitivity to punishment and sensitivity to reward questionnaire (SPSRQ) as a measure of Gray's anxiety and impulsivity dimensions. Pers Individ Dif 31:837-862.

Vogt BA (2005) Pain and emotion interactions in subregions of the cingulate gyrus. Nat Rev Neurosci 6:533-544.

Vogt BA, Gabriel M, Vogt LJ, Poremba A, Jensen EL, Kubota Y, Kang E (1991) Muscarinic receptor binding increases in anterior thalamus and 
cingulate cortex during discriminative avoidance learning. J Neurosci 11:1508-1514.

Weiland BJ, Welsh RC, Yau WY, Zucker RA, Zubieta JK, Heitzeg MM (2013) Accumbens functional connectivity during reward mediates sensationseeking and alcohol use in high-risk youth. Drug Alcohol Depend 128:130-139.

White SF, Tyler P, Botkin ML, Erway AK, Thornton LC, Kolli V, Pope K, Meffert H, Blair RJ (2016) Youth with substance abuse histories exhibit dysfunctional representation of expected value during a passive avoidance task. Psychiatry Res Neuroimaging 257:17-24.

Wiers RW, Eberl C, Rinck M, Becker ES, Lindenmeyer J (2011) Retraining automatic action tendencies changes alcoholic patients' approach bias for alcohol and improves treatment outcome. Psychol Sci 22:490-497.
Wills TA, Sandy JM, Shinar O, Yaeger A (1999) Contributions of positive and negative affect to adolescent substance use: test of a bidimensional model in a longitudinal study. Psychol Addict Behav 13:327-338.

Woo CW, Krishnan A, Wager TD (2014) Cluster-extent based thresholding in fMRI analyses: pitfalls and recommendations. Neuroimage 91:412-419.

Wu JC, Buchsbaum MS, Hershey TG, Hazlett E, Sicotte N, Johnson JC (1991) PET in generalized anxiety disorder. Biol Psychiatry 29:1181-1199.

Wunschel SM, Rohsenow DJ, Norcross JC, Monti PM (1993) Coping strategies and the maintenance of change after inpatient alcoholismtreatment. Soc Work Res Abstr 29:18-22.

Zhao XH, Wang PJ, Li CB, Hu ZH, Xi Q, Wu WY, Tang XW (2007) Altered default mode network activity in patient with anxiety disorders: an fMRI study. Eur J Radiol 63:373-378. 